\title{
Spatial Profiling Invertebrate Ganglia Using MALDI MS
}

\author{
Rebecca Kruse and Jonathan V. Sweedler \\ Department of Chemistry and the Beckman Institute, University of Illinois, Urbana, Illinois, USA
}

\begin{abstract}
The ability of MALDI TOF MS to spatially map peptides and proteins directly from a tissue is an exciting advance to imaging mass spectrometry. Recent advances in instrumentation for MS have resulted in instruments capable of achieving several micron spatial resolution while acquiring high-resolution mass spectra. Currently, the ability to obtain high quality mass spectrometric images depends on sample preparation protocols that often result in limited spatial resolution. A number of sample preparation and matrix deposition protocols are evaluated for spatial profiling of Aplysia californica exocrine gland and neuronal tissues. Such samples are different from mammalian tissues, but make good targets for method optimization because of the wealth of biochemical information available on neuropeptide processing and distribution. Electrospray matrix deposition and a variety of freezing methods have been found to be optimum for these invertebrate tissues, with the exact protocols being tissue dependent. (J Am Soc Mass Spectrom 2003, 14, 752-759) (c) 2003 American Society for Mass Spectrometry
\end{abstract}

$\mathrm{T}$ o understand the functioning of neuronal networks, knowledge of the neurotransmitters and neuromodulators used in the neuronal networks is important. The neuropeptide content of even well characterized networks from simpler organisms is not completely known, and for more complicated neuronal networks, much information needs to be obtained. Even with the wealth of genomic information available, direct biochemical measures are often required to determine the presence and particular form of the neuropeptides present throughout the central nervous system (CNS). Direct MALDI MS analysis of molluscan and insect neurons [1-13], connective nerve tissues [14], and even single peptidergic vesicles [15] provides information about gene products and their processing to bioactive neuropeptides. Mass profiling individually isolated neurons is the most common method for obtaining spatial information such as the cell-specific distribution of peptides within brain regions known as ganglia. Since neighboring neurons in ganglia may possess different biological functions and, hence, vastly different peptide profiles, mapping the contents of distinct cells and cell types within the ganglia is necessary.

Several groups have demonstrated the ability to examine sample heterogeneity and investigate peptide and protein distribution in cellular and tissue samples [16-22] with MALDI MS. To date, such work has

Published online May 29, 2003

Address reprint requests to Dr. J. V. Sweedler, Department of Chemistry and the Beckman Institute, University of Illinois, $600 \mathrm{~S}$. Mathews Avenue, 63-5, Urbana, IL 61801, USA. E-mail: sweedler@scs.uiuc.edu focused on mammalian tissues such as measuring the distribution of amyloid $\beta$ in the mouse brain [22]. These studies present the exciting ability to distinguish various tissue types within a tissue section; however, the small cell sizes in such samples do not allow for resolution at the cellular level, so that, for example, the neuropeptide in particular cells can be determined. Using the invertebrate CNS with larger neurons in the range of $15-500 \mu \mathrm{m}$ in diameter (many of which are substantially larger than the $20 \mu \mathrm{m}$ focused laser spot size used here), MALDI MS analysis should provide the capability to rapidly profile the contents of distinct cells or cell types at or near cellular image resolution without the requirement of cell isolation from the ganglion, a capability that may be especially useful for those cells that are not located near the ganglion surface.

In comparison to traditional microscopies, which often require molecule-specific preselection, in MALDI MS imaging, a focused pulsed laser beam is simply rastered across the ganglion section in successive steps, acquiring a mass spectrum at each laser position (see Figure 1). An image is then constructed from ordered arrays of position and intensity data for selected values of $m / z$.

While the overall simplicity in organization and well-characterized neural networks of invertebrate model systems offer benefits over mammalian models, the air- and solvent-sensitivity of their neurons routinely causes lyses during matrix deposition and drying, releasing cellular contents which can then mix freely with matrix solvents [17]. The millimeter-sized ganglia that contain thousands of these neurons do not 


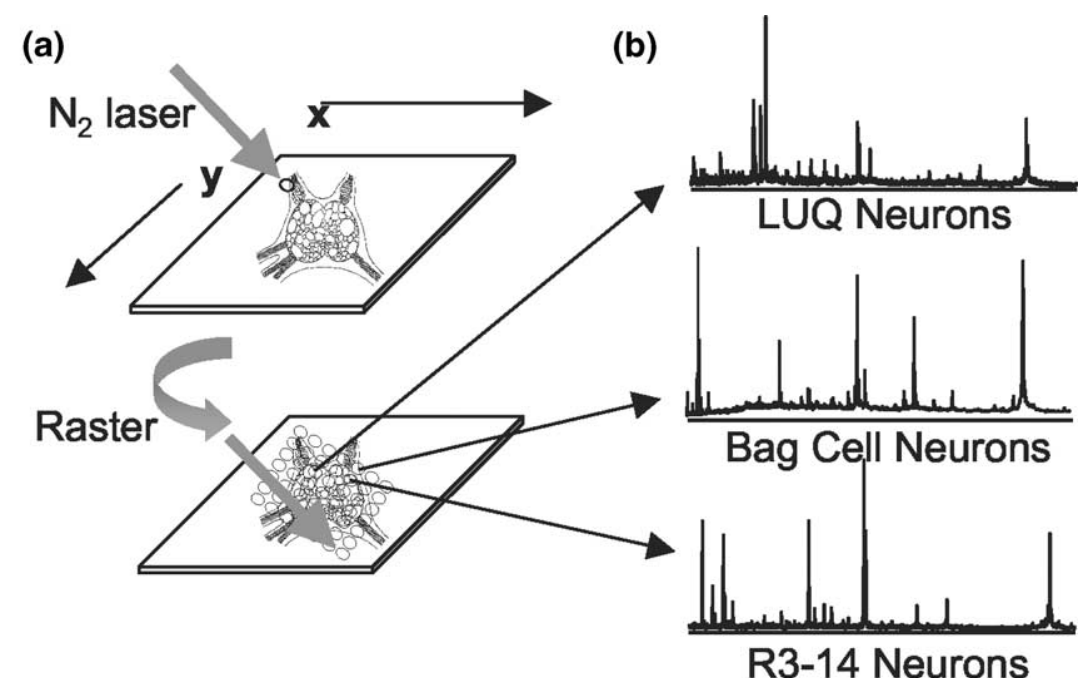

Figure 1. Schematic of the MALDI MS spatial profiling process. (a) A focused $\mathrm{N}_{2}$ laser beam is rastered across the sample-matrix surface, acquiring a mass spectrum at each position in the raster. (b) Mass spectra depict the MALDI MS peptide profiles from specific regions on the sample. Ordered arrays of intensity and position data for selected values of $\mathrm{m} / \mathrm{z}$ are used to construct images or maps of peptide location on the sample surface.

exhibit the same physical properties as those of mammalian tissues, requiring unique preparation and sectioning protocols. Here we describe preparation strategies to allow MS-based profiling of neuropeptide distributions in Aplysia ganglion sections. Traditional and novel sample preparation and sectioning strategies are presented.

\section{Experimental Section}

\section{Animals}

Aplysia californica weighing 10-200 g were obtained from Aplysia Research Facility (Miami, FL), those weighing 200-350 g were purchased from either Pacific Biomarine (Venice, CA) or Marinus (Long Beach, CA),

Table 1. Sampling strategies investigated for the preparation of Aplysia tissue and ganglia for MALDI MS imaging analysis

\begin{tabular}{|c|c|c|}
\hline Fixation technique & Sectioning technique & Comments \\
\hline & Tissue Tek O.C.T. & $\begin{array}{l}\text { No peptide signal } \\
\text { Low MW PEG signal }\end{array}$ \\
\hline & Carbowax 17000 M.W. & $\begin{array}{l}\text { No peptide signal } \\
\text { Some high MW PEG sianal }\end{array}$ \\
\hline Cold ethanol, $5 \mathrm{~min}$ & Carbowax 17000 M.W. & $\begin{array}{l}\text { Carbowax-ethanol "slush" } \\
\text { Difficulty sectioning }\end{array}$ \\
\hline Heat fixation, $<60 \mathrm{sec}$ & Carbowax 17000 M.W. & $\begin{array}{l}\text { No peptide signal } \\
\text { Some high MW PEG signal }\end{array}$ \\
\hline & Agarose & $\begin{array}{l}\text { High peptide signal } \\
\text { Thin sections down to } 10 \mu \mathrm{m}\end{array}$ \\
\hline $4 \%$ PFA in soln $\times w / 5$ rinses & Agarose & \\
\hline $\mathrm{x}=$ ultrapure water & & High peptide signal, salt \\
\hline $0.1 \mathrm{M}$ PBS & & Low peptide signal, salt \\
\hline $0.02 \mathrm{M}$ PBS $+0.1 \mathrm{M} \mathrm{NaCl}$ & & Mod peptide signal, salt \\
\hline Cold ethanol, $5 \mathrm{~min}$ & Agarose & $\begin{array}{l}\text { Excessive shrinkage, hardening } \\
\text { Difficulty sectioning }\end{array}$ \\
\hline Heat fixation & Agarose & \\
\hline $\begin{array}{l}\text { Microwave, pulsed } \\
\text { Boiling, } 5 \text { sec }\end{array}$ & $10-50 \mathrm{sec}$ & $\begin{array}{l}\text { Few peptide signals observed } \\
\text { No signal, excessive shrinkage }\end{array}$ \\
\hline \multicolumn{3}{|l|}{ Cryogenic fixation } \\
\hline Liquid nitrogen plunging: $\mathrm{N}_{2}$ (I) & Minimal Tissue Tek & $\begin{array}{l}\text { High peptide signal } \\
\text { Excess ice crystal damage }\end{array}$ \\
\hline Dry ice: $\mathrm{CO}_{2}(s)$ & Porous substrate & $\begin{array}{l}\text { High peptide signal } \\
\text { Limited ice crystal damage } \\
\text { Excess cationation adducts }\end{array}$ \\
\hline
\end{tabular}




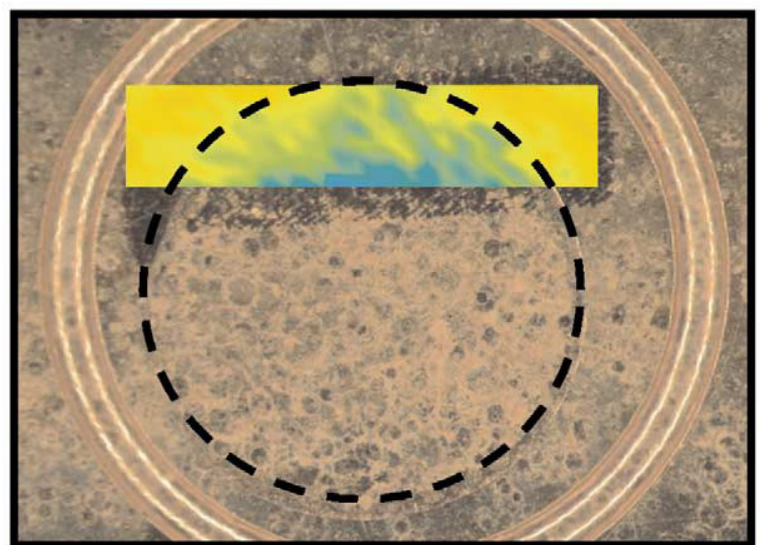

Figure 2. Electrospray matrix deposition. CHCA matrix was deposited on a dried droplet of peptide standards (dashed line) using the electrospray method. The $1600 \mu \mathrm{m} \times 400 \mu \mathrm{m}$ MALDI MS image of $\alpha$-bag cell peptide [1-8] $(1009 \mathrm{~m} / \mathrm{z})$ distribution $(0-50,000$ counts) reveals there is no significant migration of peptide signal beyond the original sample spot, but signal may be dependent upon crystal density.

and larger animals (up to $2 \mathrm{~kg}$ ) were collected from McAbee Beach in Monterey, CA. Animals were maintained in artificial seawater (Instant Ocean, Aquarium Systems, Mentor, $\mathrm{OH})$ at $14-15{ }^{\circ} \mathrm{C}$ until used.

\section{Chemicals}

Tissue Tek O.C.T., Carbowax [17 000 M.W. (poly)ethyleneglycol], and acetonitrile were obtained from Fisher Scientific (Pittsburgh, PA). Paraformaldehyde (PFA), type I and type IV agarose, $\alpha$-cyano-4-hydroxycinnamic acid (CHCA), 3,5-dimethoxy-4-hydroxycinnamic acid (sinapinic acid, SA), trifluoroacetic acid (TFA), and the chemicals used to prepare artificial seawater were from Sigma (St. Louis, MO).

\section{Sample Preparation}

Aplysia exocrine tissues and ganglia were dissected from the animal and stored in artificial seawater (ASW) up to two days until use. Tissues were then removed from ASW and fixed according to Table 1. Depending on the protocol used, the fixation and tissue stabilization occurred at room temperature, cooled $\left(0^{\circ} \mathrm{C}\right)$ ethanol, or frozen using liquid nitrogen, $\mathrm{N}_{2}(\mathrm{l})$, or dry ice, $\mathrm{CO}_{2}(\mathrm{~s})$, as detailed in Table 1 . Thin sections of the fixed and prepared tissue of between 10-30 $\mu \mathrm{m}$ thick were generated with a HM 500 OM cryostat (Michrom, Walldorf Germany) and the sections were transferred directly onto the metal MALDI sample target (PE Biosystems, Framingham, MA).

After the tissue was placed on the target, matrix was applied. The CHCA and SA matrices [15-20 mg/mL 3:2 (vol/vol) acetonitrile:0.3 \% TFA] were deposited in multiple layers with electrospray using a modified homebuilt electrophoresis apparatus described previously [23] or by micro-spotting using a capillary mi- cropipette device [15]. Briefly, for electrospray matrix deposition a syringe pump (Harvard Apparatus, South Natick, MA) delivered matrix to the tip of a $50 \mu \mathrm{m}$ i.d./150 $\mu \mathrm{m}$ o.d. capillary (Polymicro Technologies, Phoenix, AZ) at a constant flow rate of $5 \mu \mathrm{L} / \mathrm{min}$. A high voltage power supply supplied a $3 \mathrm{kV}$ potential to the capillary tip, which was positioned approximately 3 $\mathrm{mm}$ above the grounded metal sample target. During the spraying process, computer-controlled Newport actuators translated the sample target in the $\mathrm{x}$ and $\mathrm{y}$ directions at a rate of approximately $250 \mu \mathrm{m} / \mathrm{s}$. Samples were sprayed with three to five successive layers of matrix prior to drying under vacuum and storage in a vacuum desiccator until MALDI MS analysis.

\section{MALDI Analysis}

MALDI MS profiling was performed using the Voyager DE STR (PE Biosystems, Framingham, MA) with delayed ion extraction in positive ion mode. A pulsed $\mathrm{N}_{2}$ laser working at $337 \mathrm{~nm}$ was focused to $20-50 \mu \mathrm{m}$ using a variable optical aperture. The laser was rastered across the sample surface in $20-100 \mu \mathrm{m}$ steps, depending on the desired lateral image resolution and sample restrictions. Automation of data acquisition was accomplished using customized search patterns with Automatic Control Mode in the Voyager 5.1 software. An averaged spectrum was generated from 16-32 acquisitions at each position in the search pattern. MALDSPEC software described previously [17] was used to generate ordered arrays of position and intensity data from which the molecular intensity images of the sample surface were then constructed using commercial graphical software such as Excel and/or Sigma Plot.

\section{Results and Discussion}

The ultimate mass spectrometric spatial resolution obtainable depends on both the sample preparation protocols and the instrumental resolution. Commercial MALDI instruments can obtain $\sim 25 \mu \mathrm{m}$ resolution. Impressively, Spengler et al. recently described a specialized instrument for MALDI MS imaging with resolutions in the micron range [24].

Just as in other microcopic techniques such as electron microscopy and secondary ion mass spectrometry, the effective resolution can be poorer than predicted by the hardware and often depends on the particular samples being analyzed. Spatial profiling with MALDI MS requires a sample preparation protocol that avoids the relocation of peptides to ensure that the measured peptide distribution reflects that of the living biological system. While imaging of proteins with MALDI has been successfully implemented [16], the smaller, more easily redistributed peptides present special challenges. The addition of matrix has been the focus of sample preparation strategies as the liquid phase mixing of analyte and matrix is intuitively a major cause of peptide migration. Various low-volume pico-spotting 
(a)

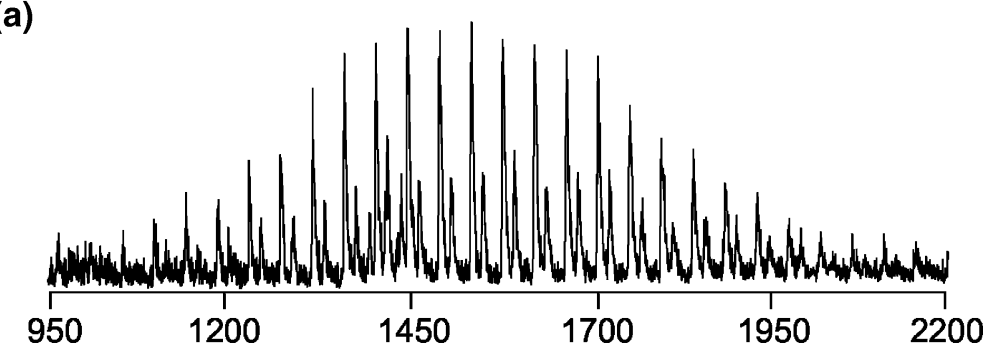

(b)
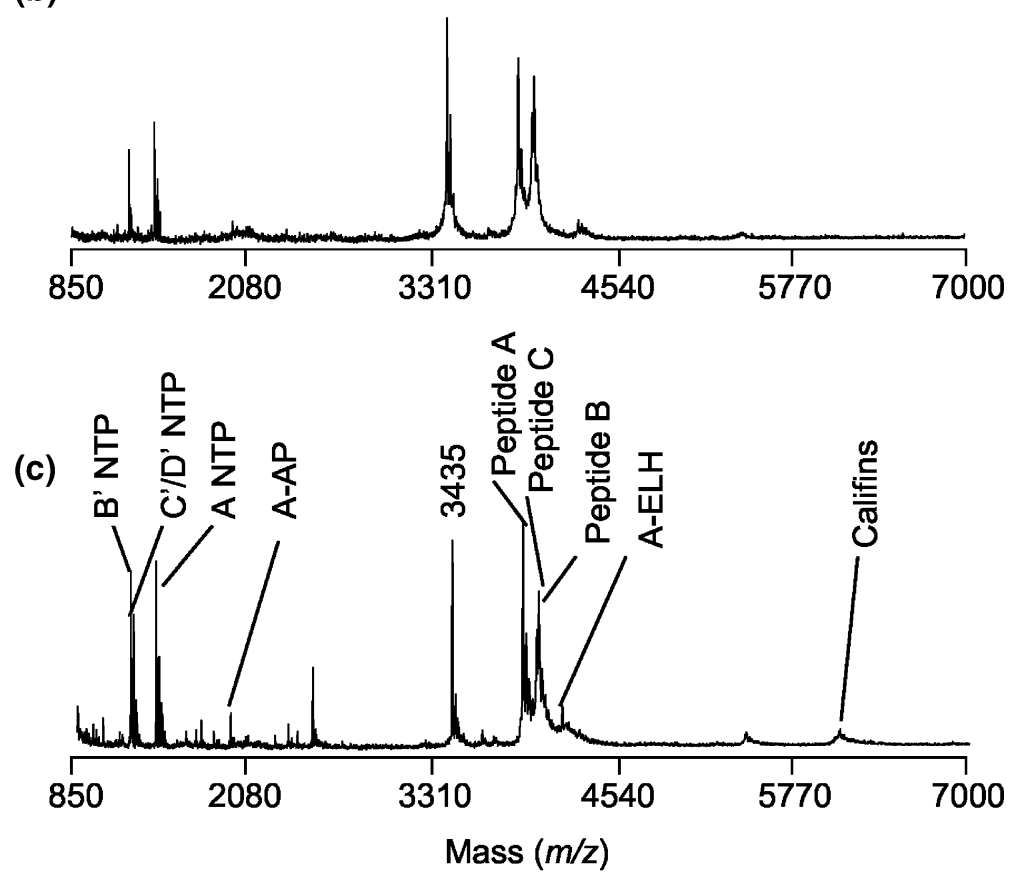

Figure 3. Investigating sample preparation with the Aplysia atrial gland. Representative MALDI mass spectra from $30 \mu \mathrm{m}$, SA micro-spotted atrial gland sections following preparation treatments (a) embedding in Tissue Tek, (b) embedding in $5 \%$ agarose, and (c) fast freezing, or $\mathrm{N}_{2}$ (l). The mass spectrum obtained following embedding in Tissue Tek is completely dominated by low M.W. PEG signals in the region of 800 to $2200 \mathrm{~m} / \mathrm{z}$. A comparison of spectra from agarose embedded and $\mathrm{N}_{2}$ (l) prepared atrial glands suggests that agarose may potentiate selective ionization of specific peptides.

and spray techniques have been developed that allow the deposition of matrix with reduced analyte migration and provide uniform matrix coverage $[9,16,18,20$, $25,26]$. In practice, however, each deposition technique possesses different characteristics that help eliminate the peptide redistribution while still providing sufficient signal and spectral resolution. In electrospray, if the spray initiates too far from the sample surface, the matrix arrives dehydrated; consequently, the analyte does not incorporate into the matrix crystals. If it initiates too close, the spray is too wet and solubilizes and redistributes peptides in the tissue.

In order to verify our experimental protocols, we analyzed several dried peptide standards on the MALDI target over which matrix had been electrosprayed. Figure 2 shows a combined photomicrograph and MALDI intensity image of a portion of the sample droplet coated with CHCA. The figure demonstrates our ability to profile samples with negligible sample spreading from the matrix deposition process observed; in this case a 50 micron sample step was used that can easily be decreased several-fold as needed with the current instrumentation. However, by visually inspecting the photomicrograph, one can clearly determine that the CHCA spray produced rather large droplets in the size range of 100 microns, approximately the diameter of a moderately sized invertebrate cell. An investigation of various matrix formulations and electrospray parameters demonstrated that the SA formulation and optimized electrospray parameters as detailed above provide a more desirable homogenous, glassy surface that is more suitable for tissue and ganglia specimens.

Even with the advent of these low-volume matrix deposition methods, careful sample preparation prior to matrix addition is important. Unfortunately, the sample preparation strategies used in traditional optical and electron microscopies are not compatible with MALDI MS imaging analysis. When used for MALDI MS, these strategies suffer from several problematic features: chemical modification of peptides, suppres- 

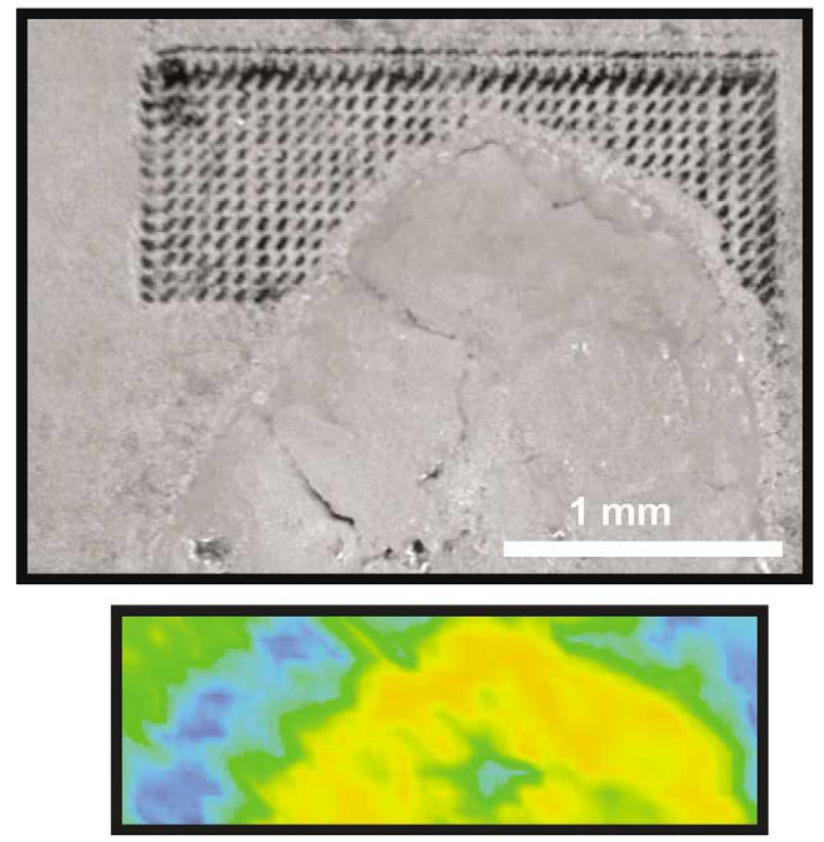

Figure 4. Profiling the peptides in the Aplysia atrial gland. (a) Optical image of a portion of a $30 \mu \mathrm{m}$, SA matrix electrosprayed atrial gland section prepared by $\mathrm{N}_{2}$ (l) following MALDI MS imaging analysis with a resolution of $100 \mu \mathrm{m}$. (b) Greyscale intensity MS image showing A-NTP $(1397 \mathrm{~m} / \mathrm{z})$ distribution $(0-$ 25,000 counts).

sion of peptide signal, and disruption of morphological integrity. Chemical fixatives acting as cross-linking agents are often precluded due to specific chemical interactions with analytes [27-30]. The reaction between the aldehyde moiety of PFA with primary or terminal amines of peptides generates a $+12 \mathrm{~m} / \mathrm{z}$ adduct per modification with MALDI MS analysis [31]. Additionally, heat fixation methods, such as microwave fixation [32], present a possibility of peptide and protein degradation during preparation. Other chemical agents commonly used in sample preparation ionize readily. For example, embedding media, which are primarily (poly) ethylene glycol (PEG)-based, dominate the mass spectra with a typical envelope of peaks that overwhelm peptide signals. Other techniques that precipitate tissue/ cell proteins tend to disrupt the morphological integrity of the sample. In the case of ethanol, the excessive volume loss, membrane surface changes, and even rupture that can occur due to the removal of water complicate the correlation of molecular images with living state structural features $[33,34]$.

Several fixative treatments of Aplysia tissues and ganglia resulted in MALDI mass spectra with significantly compromised quality and therefore were not shown. For example, in addition to the effects mentioned above, treatment with PFA and ethanol precipitated salts that lingered even after multiple rinsing steps, inhibiting matrix crystallization and causing sig- nificant signal suppression effects. Both ethanol and heat fixation caused tissue shrinkage, which complicated sectioning and also yielded MALDI mass spectra with peaks but few expected peptide signals.

Cryogenic methods [35-38] of sample preparation and sectioning appear well suited for mass spectrometric imaging with the requirement that water-containing cell and tissue samples must either be rapidly frozen and analyzed under cryogenic conditions, or dried (usually under vacuum) prior to high vacuum MALDI MS analysis [16]. Several methods of cryogenic preparation of an Aplysia tissues and ganglion have been explored. Figure 3 presents MALDI mass spectra obtained from $30 \mu \mathrm{m}$, SA micro-spotted Aplysia atrial gland sections following preparation with traditional embedding media, agarose embedding, and fast freezing. Traditional embedding media such as Tissue Tek and Carbowax (data not shown) provide substantial support and resilience to tissues during sectioning; however, as demonstrated in Figure 3a, they contain components that ionize readily, completely obscuring peptide signals. Alternative embedding media such as agarose can stabilize small and/or delicate tissues with negligible ionization interferences in the peptide mass range (Figure $3 b$ ). The fast freezing, liquid nitrogen plunging technique provides significant signal intensity and resolution with MALDI MS analysis as shown in Figure 3c. A comparison of mass spectra from agarose embedded and $\mathrm{N}_{2}$ (l) prepared atrial glands suggests that while the agarose does not suppress peptide signal by competitive ionization processes, it may enhance the selective ionization of certain peptides.

This fast freezing technique worked well for bulk tissue preparations of the atrial gland for MALDI MS analysis. The Aplysia atrial gland is an exocrine organ producing as many as 20 different peptides that influence the reproductive behavior of the animal. The chemical composition of tissue homogenates, blots, and even single vesicles has been well characterized by MALDI MS [15]. This tissue was chosen for its ease of isolation, its well-characterized peptides, and more importantly, its reported homogenous nature that allowed sample preparation procedures to be easily assessed with a resolution of $100 \mu \mathrm{m}$. The MALDI MS intensity image in Figure 4 of A-NTP $(1397 \mathrm{~m} / \mathrm{z})$ obtained from a $30 \mu \mathrm{m}$ section of $\mathrm{N}_{2}$ (l) frozen, SA electrosprayed atrial gland demonstrates several key points. First, the sample exhibits the expected signal homogeneity due to the fairly uniform nature of the tissue. Second, several areas contain reduced peptide signals, either due to unknown sample preparation artifacts or to the nature of the tissue (such as blood vessels, or regions of differing composition, etc). Finally, relocation of peptides (typically less than $100 \mu \mathrm{m}$ ) to surrounding substrate takes place, likely during the drying process or even during matrix deposition if tissues were not completely dried prior to matrix electrospray.

In contrast with the more robust Aplysia atrial gland, fast freezing was not successful for Aplysia ganglia as 


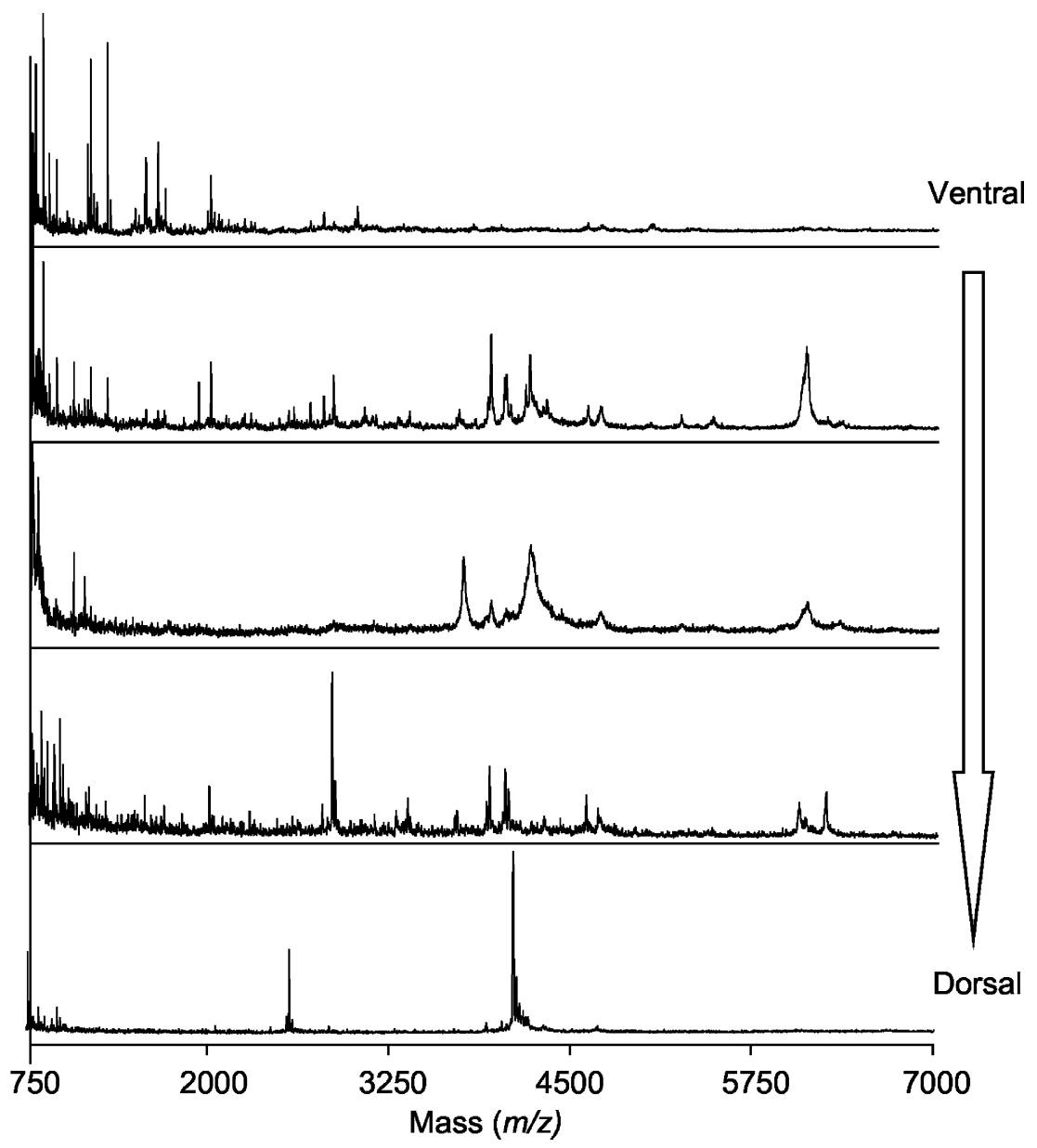

Figure 5. Profiling the Aplysia pedal ganglion. Approximately 50 sections were obtained serially every $30 \mu \mathrm{m}$ through an agarose-embedded pedal ganglion and were micro-spotted with SA matrix. The mass spectra shown above demonstrate the ability to profile neuron types without removing cells from the ganglion matrix, a capability that is especially amenable for neurons not located at the ganglion surface.

their smaller size and fragility rendered them difficult to manipulate and surfaces were prone to extensive ice crystal damage during freezing. An agarose embedding technique proved more useful as it stabilizes the small, ganglia samples, providing added support and resilience during cryosectioning. Figure 5 demonstrates the ability to profile neuron types without removing cells from the ganglion matrix, including those that are typically inaccessible because they lie beneath the ganglion surface. For proof of concept, a series of approximately 50 sections, $30 \mu \mathrm{m}$ in thickness, was obtained through the pedal ganglion (ventral to dorsal) and micro-spotted with SA. Only a few of the corresponding MALDI mass spectra are shown, but they demonstrate that at different regions, or depths, through the ganglion, neurons exhibit significant differences in peptide expression.

For these reasons, sectioning ganglia without embedding is especially desirable. We find that slowly freezing a ganglion onto a porous substrate over dry ice $\mathrm{CCO}_{2}$ (s)] in the cryostat workbox and then affixing the porous substrate to the sample mount with minimal
Tissue Tek significantly reduces sample manipulation and provides for sections as thin as $15 \mu \mathrm{m}$ that yield spectra high in peptide intensity and resolution. Because some physiological saline is required to allow for adequate adhesion to the substrate, the MALDI spectra tend to contain a large number of salt adducts. As shown in Figure 6, a MALDI mass spectrum generated from a $15 \mu \mathrm{m}$ abdominal ganglion section with SA matrix micro-spotted in the region between R3-14 neurons and bag cell clusters reveal their combined peptide profiles $[4,5]$ but with excessive cationation adducts (sodiated, potassiated, and combinations of both). Further work is necessary to investigate methods of reducing physiological saline prior to adhesion to the cellular substrate. In particular, the benefits of lower cationation need to be balanced against the potential for cellular membrane disruptions and hence, peptide relocation.

Progress has been made in designing sample preparation strategies appropriate for MALDI MS analysis of Aplysia tissues and ganglia. Based on these results, it appears that the optimum sample preparation methods are tissue specific, with various freezing protocols 


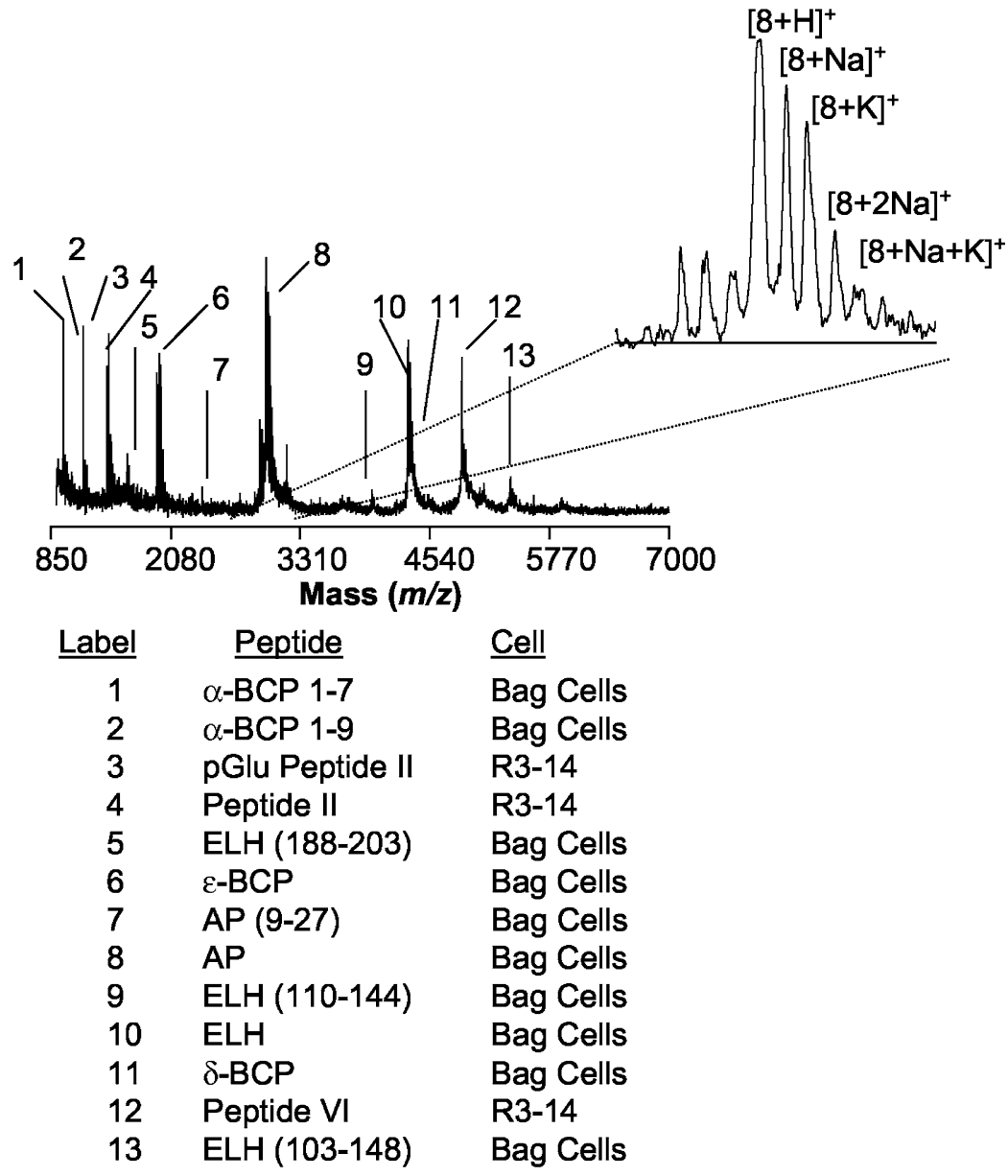

Figure 6. A representative MALDI mass spectrum from a $15 \mu \mathrm{m}$ Aplysia abdominal ganglion section prepared by slow freezing over dry ice $\left[\mathrm{CO}_{2}(s)\right]$ with SA matrix micro-spotted in the region between the R3-14 and bag cells neurons. The resulting mass spectrum shows combined peptide profiles. The inset demonstrates the extensive salt adduct formation.

working best for the Aplysia exocrine gland and ganglia samples. As such techniques are further refined, we expect that the distribution of selected peptides in particular neuronal circuits can be traced without developing immunhistochemical probes, allowing the large number of signaling molecules used in even these simple networks to be studied. Future work will continue to focus on improved matrix deposition techniques, concentrating on techniques that are compatible with cultured neurons.

\section{Acknowledgments}

The authors acknowledge Tzu-Chi Kuo and Shao-Ching Hung for assistance with modifying original data processing routines (written by Dr. Rebecca Garden and Dr. Robert Fuller) to function with Voyager 5.1/Data Explorer 4.0 acquisition and processing software. They acknowledge Jason Page for assistance with electrospray matrix deposition. They also acknowledge Pierre Chaurand of Vanderbilt School of Medicine and the faculty and staff associated with the UIUC Department of Veterinary Biosciences Center for Microscopic Imaging and Histology Laboratory for helpful discussions and suggestions pertaining to sample preparation techniques. This project was supported by the National Institute of
Neurological Disease and Stroke (NS31609) and the National Institute of Drug Abuse (DA14879).

\section{References}

1. van Veelan, P. A.; Jimenez, C. R.; Li, K. W.; Wildering, W. C.; Geraerts, W. P. M.; Tjaden, U. R.; van der Greef, J. Direct Peptide Profiling of Single Neurons by Matrix-Assisted LaserDesorption Ionization Mass Spectrometry. Org. Mass. Spectrom. 1993, 28, 1542 .

2. Jimenez, C. R.; Li, K. W.; Dreisewerd, K.; Spijker, S.; Kingston, R.; Bateman, R. H.; Burlingame, A. L.; Smit, A. B.; van Minnen, J.; Geraerts, W. P. M. Direct Mass Spectrometric Peptide Profiling and Sequencing of Single Neurons Reveals Differential Peptide Patterns in a Small Neuronal Network. Biochemistry 1998, 37, 2070.

3. Floyd, P. D.; Li, L.; Rubakhin, S.; Sweedler, J. V.; Horn, C. C.; Kupferman, I.; Alexceeva, V.; Ellis, T.; Dembrow, N. C.; Weiss, K. R.; Vilim, F. S. Insulin Prohormone Processing, Distribution, and Relation to Metabolism in. Aplysia californica. J. Neuroscience. 1999, 19, 7732-7741.

4. Garden, R. W.; Moroz, T. P.; Gleeson, J. M.; Floyd, P. D.; Li, L.; Rubakhin, S. S.; Sweedler, J. V. Formation of N-Pyroglutamyl Peptides from N-Glu and N-Gln Precursors in Aplysia Neurons. J. Neurochem. 1999, 72, 676-681. 
5. Garden, R. W.; Shippy, S. A.; Li, L.; Moroz, T. P.; Sweedler, J. V. Proteolytic Processing of the Aplysia Egg-Laying Hormone Prohormone. Proc. Natl. Acad. Sci. U.S.A. 1998, 95, 3972-3977.

6. Li, L.; Romanova, E. V.; Rubakhin, S. S.; Alexeeva, V.; Weiss, K. R.; Vilim, F. S.; Sweedler, J. V. Peptide Profiling of Cells with Multiple Gene Products: Combining Immunochemistry and MALDI Mass Spectrometry with On-Plate Microextraction. Anal. Chem. 2000, 72, 3867-3874.

7. Li, L.; Garden, R. W.; Sweedler, J. V. Single-Cell MALDI: A New Tool for Direct Peptide Profiling. Trends Biotechnol. 2000, 18, 151-160.

8. Li, L.; Garden, R. W.; Romanova, E. V.; Sweedler, J. V. In Situ Sequencing of Peptides from Biological Tissues and Single Cells Using MALDI-PSD/CID Analysis. Anal. Chem. 1999, 71, 5451-5458.

9. Rubakhin, S. S.; Li, L.; Moroz, T. P.; Sweedler, J. V. Characterization of the Aplysia californica Cerebral Ganglion F Cluster. J. Neurophysiol. 1999, 8, 1251-1260.

10. Vilim, F. S.; Alexeeva, V.; Moroz, L. L.; Li, L.; Moroz, T. P.; Sweedler, J. V.; Weiss, K. R. Cloning, Expression and Processing of the CP2 Neuropeptide Precursor of Aplysia. Peptides 2001, 22, 2027-2038.

11. Predel, R.; Eckert, M.; Holman, G. M. The Unique Neuropeptide Pattern in Abdominal Perisympathetic Organs of Insects. Annu. NY Acad. Sci. 1999, 897, 282.

12. Nachman, R. J.; Coast, G. M.; Tichy, S. E.; Russell, D. H.; Miller, J. A.; Predel, R. Identification of the Abundant Neuropeptide from Abdominal Perisympathetic Organs of Locusts. Peptides 2002, 23, 1885.

13. Li, L.; Pulver, S. R.; Kelley, W. P.; Thirumalai, V.; Sweedler, J. V.; Marder, E. Orcokinin Peptides in Developing and Adult Crustacean Stomatogastric Nervous Systems and Pericardial Organs. J. Compar. Neurol. 2002, 444, 227.

14. Li, L.; Garden, R. W.; Moroz, T. P.; Floyd, P. D.; Weiss, K. R.; Sweedler, J. V. Mass Spectrometric Survey of Interganglionically Transported Peptides in Aplysia. Peptides 1998, 19, 14251433.

15. Rubakhin, S. S.; Garden, R. W.; Fuller, R. R.; Sweedler, J. V. Measuring the Peptides in Individual Organelles with Mass Spectrometry. Nature Biotechnol. 2000, 18, 172-175.

16. Todd, P. J.; Schaaff, T. G.; Chaurand, P.; Caprioli, R. M. Organic Ion Imaging of Biological Tissue with Secondary Ion Mass Spectrometry and Matrix-Assisted Laser Desorption/ Ionization. J. Mass Spectrom. 2001, 36, 355-369.

17. Garden, R. W.; Sweedler, J. V. Heterogeneity within MALDI Samples as Revealed by Mass Spectrometric Imaging. Anal. Chem. 2000, 72, 30-36.

18. Caprioli, R. M.; Farmer, T. B.; Gile, J. Molecular Imaging of Biological Samples: Localization of Peptides and Proteins Using MALDI-TOF MS. Anal. Chem. 1997, 69, 4751-4760.

19. Chaurand, P.; Stoeckli, M. Caprioli R. M. Direct Profiling of Proteins in Biological Tissue Sections by MALDI Mass Spectrometry. Anal. Chem. 1999, 71, 5263-5270.

20. Koomen, J. M.; Stoeckli, M.; Caprioli, R. M. Mapping of Surrogate Markers of Cellular Components and Structures Using Laser Desorption/Ionization Mass Spectrometry. J. Mass Spectrom. 2000, 35, 258-264.

21. Stoeckli, M.; Chaurand, P.; Caprioli, R. M. Imaging Mass Spectrometry: A New Technology for the Analysis of Protein Expression in Mammalian Tissues. Nature Med. 2001, 7, 493496.
22. Stoekcli, M. Molecular Imaging of Amyloid B Peptides in Mouse Brain Sections Using Mass Spectrometry. Anal. Biochem. 2002, 311, 33-39.

23. Page, J.; Sweedler, J. V. Direct Cellular Assays Using Off-Line Capillary Electrophoresis with Matrix-Assisted Saser Desorption/Ionization Time-of-Flight Mass Spectrometry. Analyst 2000, 125, 555-561.

24. Spengler, B.; Hubert, M. Scanning Microprobe Matrix-Assisted Laser Desorption Ionization (SMALDI) Mass Spectrometry: Instrumentation for Sub-Micrometer Resolved LDI and MALDI Surface Analysis. J. Am. Soc. Mass Spectrom. 2002, 13, 735-748.

25. Bergquist, J. Cells on the Target-Matrix-Assisted Laser-Desorption/ionization Time-of-Flight Mass-Spectrometric Analysis of Mammalian Cells Grown on the Target. Chromatographia 1999, 49, S41-48.

26. Little, D. P.; Cornish, T. J.; O’Donnell, M. J.; Braun, A.; Cotter, R. J.; Koster, H. MALDI on a Chip: Analysis of Arrays of Low-Femtomole to Subfemtomole Quantities of Synthetic Oligonucleotides and DNA Diagnostic Products Dispensed by a Piezoelectric Pipet. Anal. Chem. 1997, 69, 4540-4546.

27. Brandtzaeg, P. In Techniques in Immunochemistry, Vol. I.; Bullock G. R. Petrusz, P., Eds.; Academic Press: London, 1982; pp 1-75.

28. Hassel, J.; Hand, A. R. Tissue Fixation with Diimidoesters as an Alternative to Aldehydes. I. Comparison of Cross-Linking and Ultrastructure Obtained with Dimethylsuberimidate and Glutaraldehyde. J. Histochem. Cytochem. 1974, 22, 223-239.

29. Rubbi, C. P.; Qiu, J.; Rickwood, D. An Investigation into the Use of Protein Cross-Linking Agents as Cell Fixatives for Confocal Microscopy. Eur. J. Histochem. 1994, 38, 269-280.

30. Sung, H. W.; Liang, I. L.; Chen, C. N.; Huang, R. N.; Liang, H. F. Stability of a Biological Tissue Fixed with a Naturally Occurring Cross-Linking Agent (Genipin). J. Biomed. Mater. Res. 2001, 55, 538-546.

31. Redeker, V.; Toullec, J. Y.; Vinh, J.; Rossier, J.; Soyez, D. Combination of Peptide Profiling by Matrix-Assisted Laser Desorption/Ionization Time-of-Flight Mass Spectrometry and Immunodetection on Single Glands or Cells. Anal. Chem. 1998, 70, 1805-1811.

32. Chaudhari, K.; Chattopadhyay, A.; Dutta, S. K. Microwave Technique in Histopathology and its Comparison with the Conventional Technique. Indian J. Pathol. Microbiol. 2000, 43, 387-394.

33. Castejon, O. J. Sample Preparation Techniques for Conventional and High-resolution Scanning Electron-Microscropy of the Central Nervous System-the Cerebellum as a Model. Scan. Microsc. 1993, 7, 725-740.

34. Wilson, H. H. B.; Chauhan, J.; Kerry, P. J.; Evans, J. G. Ethanol Vapour-Fixation of Rat Lung for Immunocytochemistry Investigations. J. Immunol. Methods 2001, 247, 187-190.

35. Chaurand, P.; Caprioli, R. M. Direct Profiling and Imaging of Peptides and Proteins from Mammalian Cells and Tissue Sections by Mass Spectrometry. Electrophoresis 2002, 23, 31253135.

36. Ameye, L.; Hermann, R.; Dubois, P.; Flamming, P. Ultrastructure of the Echinoderm Cuticle after Fast-Freezing/Freeze Substitution and Conventional Chemical Fixations. Microsc. Res. Tech. 2000, 48, 385-393.

37. Dykstra, M. J. Biological Electron Microscopy: Theory, Techniques, and Troubleshooting. Plenum Press: New York, 1999; 247-273.

38. Nicolas, G. Advantages of Fast-Freeze Fixation Followed by Freeze-Substitution for the Preservation of Cell Integrity. J. Electron. Microsc. Tech. 1991, 18, 395-405. 